\title{
A SIMPLIFIED SCORING SYSTEM FOR THE POST-OPERATIVE RECOVERY ROOM
}

\author{
D.J. STEWARD
}

SEveral MEthods have been described for assessing objectively the progress of recovery from surgical anaesthesia. ${ }^{1-3}$ These post-anaesthesia recovery scores are similar in principle to the Apgar score ${ }^{4}$ used to evaluate the condition of the newborn. A serious limitation of these scoring systems is that they include factors, such as colour, which are difficult to interpret consistently, and factors such as blood pressure which may have little constant relation to recovery from general anaesthesia.

A new and simple scoring system permits a simple record of important stages of recovery from general anaesthesia.

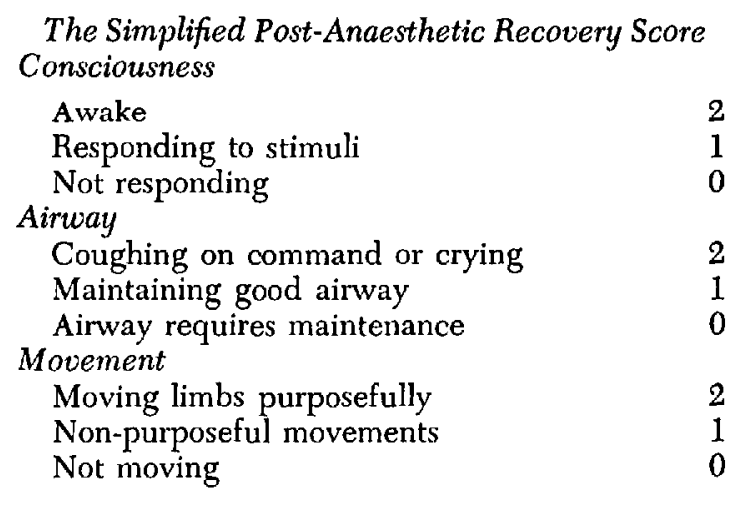

TOTAL

Figure 1

The factors scored have been chosen because they can be easily classified into well-recognized stages, and because they demonstrate a series of progressive changes directly related to the recovery process. These stages also indicate the significant return of protective functions. A maximum of two points are allocated under each of three headings making possible a total score of six for a fully recovered patient. A score of zero would be assigned to an unresponsive, immobile patient whose airway requires maintenance.

Scores should be assigned on admission to the post-anaesthetic room when the routine vital signs are measured. Repeated scoring should be performed at suitable intervals thereafter, more frequently during the immediate recovery stages, and again on discharge to the ward or home.

Department of Anaesthesia, The Hospital for Sick Children, and Department of Anaesthesia, University of Toronto, Toronto, Ontario, Canada. 


\section{RECOVERY ROOM SCORES}

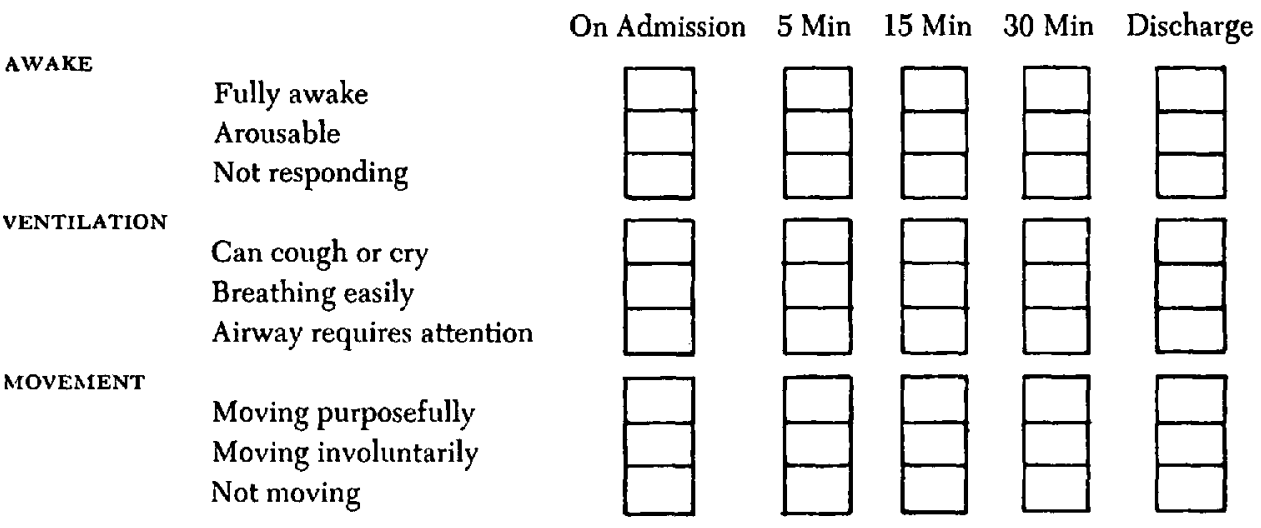

Figure 2

\section{Discussion}

The early post-operative period is potentially the most dangerous for the surgical patient. Close supervision by skilled nursing staff is essential if serious complications are to be avoided. In the past, the record of the patient's progress during this period usually consisted of "vital signs" and accompanying nurse's notes. These often failed to communicate a clear picture of the status of the patient.

The Recovery Score provides a uniform and definitive account of the progress of the patient through important stages in his recovery from general anaesthesia. It also establishes a routine of repeated re-evaluation which should result in improved patient supervision. The described system is simple enough that it will neither distract the nurse from watching the patient nor impose an extra burden upon her. The system has been accepted well by the post-anaesthetic room nursing staff and is now incorporated into the Record Sheet (Figure 2).

The retrospective analysis of the exact status of a patient at a given time after operation may, in rare cases, have an important medico-legal significance. The use of such scores is valuable as a research tool in comparing recovery following various techniques of general anaesthesia.

\section{SUMMARY}

A new and very simple scoring system for recording post-anaesthetic recovery is described. When numerical values are assigned to factors indicating recovery, progress or lack of it is obvious. The record may have medico-legal value. It can be incorporated into the Recovery Room Record.

\section{REFERENCES}

1. Cafigan, G., Keeri-Szanton, M., \& Lavellee, J.P. Postanaesthetic scoring system. Anesthesiology 25: 396-397 (1964).

2. Aldrete, J.A. \& Kroulik, D. A postanaesthetic recovery score. Anesth. Analg. 49: 924$934(1970)$. 
3. FiguenoA, M., Jr. The postanaesthesia recovery score: A second look. South. Med. J. 65: 791-795 (1972).

4. Apgar, V., Holaday, D.A., James, L.S., Weisbrot, L.M., \& Berrien, C. Evaluation of the newborn infant - Second report. J.A.M.A. 168: 1988 (1958). 